\title{
ANALISIS PELAKSANAAN \\ KEBIJAKAN BANTUAN PROGRAM KELUARGA HARAPAN
}

\author{
Faizal Anwar ${ }^{1}$, Nanik Untari ${ }^{2}$ \\ Univesitas Muhamamadiyah Bengkulu ${ }^{1,2}$ \\ faizal2020123@gmail.com $^{1}$
}

\begin{abstract}
ABSTRAK
Tujuan penelitian ini adalah untuk mengetahui pelaksanaan kebijakan bantuan Program Keluarga Harapan serta ingin mengetahui apa saja faktor yang menghambat dalam pelaksanaan Program Keluarga Harapan (PKH) di Desa Mesigit. Metode dalam penelitian ini menggunakan penelitian kualitatif. Hasil penelitian menunjukkan bahwa implimentasi kebijakan Program Keluarga Harapan telah berjalan dengan baik, namun yang menjadi menghambatan dalam pelaksanaan program keluarga harapan kurangnya koordinasi pendamping PKH kepada pemerintah desa. Simpulan penelitian ini bahwa pelaksanaan Program Keluarga Harapan (PKH) sudah berjalan dengan baik karena memiliki empat indikator implementasi kebijakan seperti: komunikasi, sumberdaya, disposisi dan struktur birokrasi. Sedangkan faktor penghambatnya adalah kurangnya kesadaran dan minat masyarakat tentang $\mathrm{PKH}$, fasilitas jaringan telekomunikasi dan belum terlaksannya kegiatan rapat, tidak adanya koordinasi dari pendamping $\mathrm{PKH}$.
\end{abstract}

Kata Kunci: Kebijakan, Kemiskinan, Program,

\begin{abstract}
The purpose of this study was to determine the implementation of the Family Hope Program Assistance Policy and to want to know what factors hindered the implementation of the Family Hope Program (PKH) in Mesigit Village. The method in this research uses qualitative research. The results showed that the implementation of the Family Hope Program policy has gone well, but that has become an obstacle in the implementation of the Hope Family Program coordinating PKH facilitators to the village government. The conclusion of this research is that the implementation of the Family Hope Program (PKH) has been going well because it has four indicators of policy implementation such as: communication, resources, disposition and bureaucratic structure. While the inhibiting factors are the awareness and interest of the community about PKH, telecommunications network facilities and the absence of meeting activities, there is no coordination from PKH facilitators.
\end{abstract}

Keywords: Policy, Poverty, Program. 


\section{PENDAHULUAN}

Kemiskinan merupakan isu strategis dalam pembangunan di sebuah Negara, namun kemiskinan sering kali menjadi hambatan bagi Negara berkembang dalam proses pembangunan seperti di Indonesia. Kemiskinan memang pekerjaan besar bagi pemerintah, berbagai cara telah dilakukan tapi masih belum bisa menyelesaikan permasalahan ini. Kemiskinan merupakan masalah yang ditandai oleh berbagai hal antara lain rendahnya kualitas hidup penduduk, terbatasnya kecukupan dan mutu pangan, terbatasnya dan rendahnya mutu layanan kesehatan, gizi anak, dan rendahnya mutu layanan pendidikan.

Kemiskinan menjadi perhatian pemerintah pusat dan pemerintah daerah. Karena salah satu faktor penyebab ketertinggalan dan penghambat dalam pembangunan suatu bangsa adalah tingginya angka kemiskinan (Darmi, 2019). Kemiskinan yang terjadi dalam suatu negara merupakan suatu masalah yang sangat serius, karena kemiskinan dapat memicu banyak persoalan yang mengakibatkan masyarakat sulit untuk memenuhi kebutuhan hidupnya.

Badan Pusat Statistik (BPS) Indonesia menyatakan pada tahun 2018 jumlah penduduk Indonesia mencapai 265 juta jiwa, dengan jumlah penduduk miskin di Indonesia pada bulan Maret 2018 mencapai 9,82 persen atau setara dengan 25,92 juta orang. Dinas Kominfo dan Statistik Provinsi Bengkulu menyatakan jumlah penduduk Provinsi Bengkulu pada tahun 2018 mencapai 1.999 .539 juta jiwa dan untuk jumlah penduduk miskin di Provinsi Bengkulu yaitu tercatat pada Maret 2018 mencapai 15,43 persen setara dengan 301.801 orang. Selama ini berbagai upaya telah dilakukan untuk mengurangi kemiskinan melalui penyediaan kebutuhan pangan, layanan kesehatan dan pendidikan, perluasan kesempatan kerja dan sebagainya. Di Negara Indonesia saat ini sudah banyak program-program bantuan yang telah dilaksanakan untuk mengurangi angka kemiskinan salah satunya adalah Program Keluarga Harapan (PKH).

Program Keluarga Harapan $(\mathrm{PKH})$ adalah program perlindungan sosial yang memberikan bantuan uang tunai kepada Rumah Tangga Sangat Miskin (RTSM) dengan syarat dapat memenuhi kewajiban terkait pendidikan dan kesehatan. Progaram Keluarga Harapan (PKH) mulai dilaksanakan oleh Pemerintah Indonesia pada tahun 2007.

PKH bertujuan mengurangi beban Rumah Tangga Sangat Miskin (RTSM) dan diharapkan dapat memutus mata rantai kemiskinan antar generasi, sehingga generasi berikutnya dapat keluar dari kemiskinan. PKH juga mendukung pencapaian Tujuan Pembangunan Berkelanjutan atau Sustainable Development Goals (SDGs). Program ini dikenal sebagai Program Bantuan Tunai Bersyarat. Persyaratan tersebut berupa kehadiran di fasilitas pendidikan (anak usia sekolah) maupun kehadiran di fasilitas kesehatan (Anak Balita dan Ibu hamil). Tujuan PKH adalah mengurangi angka kemiskinan dan memutus rantai kemiskinan antar generasi, meningkatkan kualitas sumber daya manusia, serta mengubah perilaku yang kurang mendukung peningkatan kesejahteraan.

Sasaran PKH yang sebelumnya berbasis Rumah Tangga menjadi berbasis Keluarga. Perubahan ini bertujuan untuk mengakomodasi prinsip keluarga yaitu 1 orang tua yang memiliki tanggung jawab terhadap pendidikan, kesehatan, kesejahteraan, dan masa depan anak. Sehingga keluarga adalah unit yang relevan untuk peningkatan kualitas sumber daya manusia dalam upaya memutus rantai kemiskinan antar generasi. Beberapa keluarga dapat berkumpul dalam 1 rumah tangga.

Kabupaten Bengkulu Utara adalah sebuah kabupaten di provinsi Bengkulu, kabupaten yang terletak di kawasan pesisir Pantai Barat Sumatra dengan ibu kotanya Arga Makmur. Kota Arga Makmur berjarak sekitar $60 \mathrm{~km}$ dari Kota Bengkulu. Kabupaten Bengkulu Utara terbagi dalam 17 kecamatan, dari 17 Kecamatan terdapat 5 kelurahan, 224 desa definitif.

Kabupaten Bengkulu Utara termasuk di dalam Kabupaten penerima bantuan PKH, pada tahun 2018 penerima mencapai hingga 91.809 keluarga, namun di tahun 2019 
memiliki penurunan yaitu sebanyak 765 penerima menjadi 91.044 KPM (keluarga penerima manfaat) yang tersebar di kabupaten dan kota. Kabupaten Bengkulu Utara di katagorikan kabupaten penerima PKH terbanyak mencapai 16.795 KPM. Kabupaten Bengkulu Utara tercatat sebagai penerima Program Keluarga Harapan (PKH) saat ini sebanyak 1.700 jiwa. Penerima PKH di Bengkulu Utara yaitu tergolong di dalam keluarga kurang mampu, memiliki anak yang masih sekolah, ibu hamil dan lanjut usia (Lansia) dengan jumlah bantuan yang bervariasi. Namun dari bulan Januari banyak keluarga yang mengundurkan diri dari PKH yaitu ada lebih $100 \mathrm{KPM}$. Keluarga penerima PKH yang mengundurkan diri dengan langsung datang ke Dinas Sosial untuk menyatakan bahwa telah berhenti menerima PKH dan meminta dicoret namanya dari data penerima PKH.

Keluarga penerima PKH tercatat paling banyak mengundurkan diri yaitu di Desa Taba Tebilang yang terletak di jalan lintas Argamakmur sebanyak 49 penerima PKH. Namun di perkirakan jumlah yang mengundurkan diri akan terus bertambah karena banyak dari mereka tidak termasuk di dalam kategori keluarga/seseorang yang tidak mampu dan rentan dengan pendidikan, kesehatan. (Harian Rakyat Bengkulu.com, 06 Juli 2019). Dari beberapa Kecamatan yang ada di Kabupaten Bengkulu Utara ini Kecamatan yang termasuk sebagai penerima bantuan PKH yaitu Kecamatan Air Padang. Kecamatan Air Padang terdiri dari 10 desa. Salah satu desa yang ada di kecamatan Air Padang yaitu Desa Mesigit.

Desa Mesigit merupakan salah satu desa yang mempunyai jumlah keluarga miskin cukup banyak sehingga terdapat beberapa anak-anak yang putus sekolah. Dengan bantuan PKH ini bisa mengurangi angka kemiskinan dan meningkatkan sumber daya manusia seperti pendidikan, kesehatan dan kesejahteraan sosial pada kelompok keluarga miskin.

Sebenarnya penelitian tentang Pelaksanaan Kebijakan Bantuan Program Keluarga Harapan ini sudah terlebih dahulu di teliti oleh Iqbal Nugraha, 2018 dengan judul "Implementasi Program Keluarga harapan Oleh Unit Pelaksana PKH (UPPKH) Dinas Sosial Kabupaten Lampung Utara". Fokus dari penelitian ini untuk meneliti hubungan Program Keluarga Harapan sebagai sebuah Kebijakan Publik dengan realitas implementasi yang dilakukan oleh Implementor PKH.

Hasil pengkajian terdahulu memberikan gambaran implementasi program $\mathrm{PKH}$ memiliki hambatan meliputi kendala dalam pelaksanaan penetapan Rumah Tangga Sasaran (RTS) akibat sumber data yang tidak akurat, keterlambatan pelaksanaan kegiatan pemutahiran data akibat tidak terpenuhinya sebagian prasyarat administratif, serta keterlambatan pelaksanaan verifikasi komitmen akibat kinerja oknum petugas pendamping PKH yang kurang optimal, serta koordinasi antar lembaga pendukung yang belum maksimal.

Kajian ini untuk mengetahui pelaksanaan PKH yang telah terlaksana dengan baik atau tidak baiknya dari Kebijakan Program Keluarga Harapan dan ingin melihat faktorfaktor penghambat pelaksanaan PKH. Hal ini yang menjadi dasar untuk dalam Pelaksanaan Kebijakan Bantuan Program Keluarga Harapan Di Desa Mesigit Air Padang Kabupaten Bengkulu Utara.

\section{METODE PENELITIAN}

Penelitian ini bertujuan untuk mengetahui Pelaksanaan Kebijakan Bantuan Program Keluarga Harapan di desa Mesigit Air Padang Kabupaten Bengkulu Utara. Metode penelitian yang digunakan dalam penelitian ini adalah pendekatan kualitatif dengan pengkajian deskriptif yang dituangkan dalam bentuk uraian. Menurut Bogdan penelitian kualitatif diibaratkan sebagai seni seperti orang asing yang menonton wayang kulit atau peristiwa lain. Ia belum tahu apa, mengapa, bagaimana wayang kulit itu, ia akan tahu setelah ia melihat, mengamati, dan menganalisis dengan serius (Moleong, 2009) 


\section{HASIL PENELITIAN}

Berdasarkan hasil wawancara secara mendalam dengan informan, secara umum dapat diketahui bahwa tujuan penelitian ini adalah untuk menganalisis pelaksanaan kebijakan bantuan program keluarga harapan di desa Mesigit. Selain itu juga untuk mengetahui faktor penghambat pelaksanaan kebijakan bantuan program keluarga harapan di Desa Mesigit. Dari hasil penelitian kemudian dibahas beberapa faktor yang dapat mempengaruhi implementasi kebijakan publik menurut George Edward III, sebagaimana di kutip oleh Indiahono (2009) mengatakan bahwa keberhasilan implementasi kebijakan publik akan berhasil apabila dipengaruhi beberapa faktor yaitu, komunikasi, sumber daya, disposisi dan struktur birokrasi.

\section{PEMBAHASAN}

\section{Analisis Pelaksanaan Kebijakan Bantuan Program Keluarga Harapan}

Analisis pelaksanaan kebijakan bantuan Program Keluarga Harapan di desa Mesigit kecamatan Air Padang kabupaten Bengkulu Utara yang terkait dengan kebijakan pengelolaan bantuan Program Keluarga Harapan (PKH) dengan indikator sebagai berikut:

\section{Komunikasi}

Setiap kebijakan akan dapat terlaksana dengan baik jika terjadi komunikasi yang efektif antara pelaksana dan masyarakat yang menerima. Menurut George C. Edward III (2008) dalam melaksanakan suatu kebijakan maka pola komunikasi menjadi hal yang sangat penting dan berkontribusi pada suksesnya pelaksanaan kebijakan program PKH.

Komunikasi juga sangat penting dalam menunjang suatu pelaksanaan program untuk menyampaikan bagaimana struktural dan syarat-syarat administrasi yang harus dipahami oleh penerima PKH. Komunikasi antara pendamping PKH kabupaten dengan pendamping $\mathrm{PKH}$ desa perlu bersinergitas untuk menghasilkan penerima $\mathrm{PKH}$ yang benar-benar tepat sasaran. Adapun sosialisasi yang sering dilakukan antara lain, kelengkapan syarat penerima bantuan, seperti mengadakan pertemuan di setiap bulannya apabila terdapat perubahan tentang $\mathrm{PKH}$, pertemuan dan rapat juga di tujukan agar terjadinya komunikasi yang baik antara pelaksana $\mathrm{PKH}$ dan masyarakat penerima $\mathrm{PKH}$.

Berdasarkan Permensos Nomor 1 tahun 2018 dapat di lihat dari mekanisme penyaluran bantuan sosial PKH secara non-tunai sebagaimana yang dimaksud dalam pasal 37 ayat 1 yang mengharuskan diadakannya sosialisasi sebagai edukasi kepada masyarakat. Dari sosialisasi tentang persyaratan yang telah dilakukan tersebut maka tidak ada lagi penerima PKH yang bukan pada tempatnya atau tidak tepat sasaran.

Pendamping PKH bukan hanya sebagai penyalur dalam pencairan dana saja namun pendamping $\mathrm{PKH}$ juga memiliki hubungan komunikasi dengan pihak pendidikan dan kesehatan seperti sekolah dan posyandu yang ada secara turun langsung di lapangan agar mengetahui apakah dana yang disalurkan kepada penerima bantuan PKH digunakan dengan tepat atau tidak. Pendapat tentang mekanisme sosialisasi yang dilakukan oleh pelaksana PKH terhadap masyarakat desa Mesigit sudah berjalan dengan baik, hanya saja pelaksanaannya masih ada hambatan atau kendala yang terjadi, baik dari masyarakat maupun anggota pelaksana PKH. Hal ini bisa dikatakan bahwa pelaksanaan kebijakan bantuan PKH di desa Mesigit menggunakan indikator komunikasi dalam pelaksanaan $\mathrm{PKH}$ di desa Mesigit untuk menjadi pendukung suatu program tersebut.

\section{Sumber Daya}

Sumber daya manusia yang mempunyai sangat mendukung berjalannya suatu program pemerintah kabupaten menjadi program yang berhasil. SDM yang tinggi membuat suatu program pemerintahan menjadi mudah untuk menyentuh lapisan masyarakat terendah tentu menjadi tujuan penting dari sebuah program (Darmi, 2017). 
Menurut George C. Edward III (2008) Sumber daya menunjukkan setiap kebijakan harus didukung oleh sumber daya yang memadai, baik sumber daya manusia maupun sumber daya finansial (Darmi, 2018) .

Data di lapangan menunjukkan bahwa pendamping PKH sangat dituntut untuk memiliki SDM yang tinggi agar mampu menyampaikan informasi yang akurat terhadap penerima manfaat bantuan sosial seperti PKH ini, salah satu contoh pentingnya SDM yang tinggi adalah pendamping PKH kabupaten dituntut memiliki ijazah terendah minimal tamat SMA/sederajat bahkan pelaksana PKH yang mendampingi desa Mesigit memiliki ijazah srata 1. Pendamping PKH sangat berperan penting di dalam suatu program PKH karena pendamping $\mathrm{PKH}$ adalah sebagai pendukung pertama dalam menunjang suatu program agar terlaksana dengan baik.

Hasil wawancara dan observasi peneliti di lapangan, bahwa pelaksanaan PKH sudah berjalan dengan baik, dikatakan baik karena pendamping PKH memang melaksanakan kegiatannya sesuai dengan tugas yang telah di tetapkan, pendamping PKH sebelum terjun langsung ke lapangan untuk melaksanakan tugas sudah terlebih dahulu mengikuti pelatihan-pelatihan yang di adakan langsung oleh Kemensos. Pendamping PKH juga menyiapkan sarana yang mempermudah dalam kegiatan PKH ini seperti membawa alat mesin debit langsung ke desa ketika pencairan dana PKH.

Pemerintah desa juga berperan penting untuk mendukung pelaksanaan $\mathrm{PKH}$ dengan menerima baik pelaksana $\mathrm{PKH}$ untuk mendampingi masyarakatnya yang sebelumnya sudah terlebih dahulu mengadakan rapat kepada pemerintah setempat membahas tentang kebijakan bantuan PKH dan pemerintah desa memfasilitasi dalam pelaksanaan PKH seperti menyediakan tempat untuk pertemuan, memberikan data keluarga miskin kepada pendamping $\mathrm{PKH}$, dan memfasilitasi mesin foto copy untuk penerima $\mathrm{PKH}$ mengurus syarat-syarat $\mathrm{PKH}$. Hal ini bisa dikatakan bahwa pelaksanaan kebijakan bantuan PKH di desa Mesigit dalam indikator sumber daya sudah berjalan dengan baik karena mendapatkan dukungan dari pemerintah desa dengan menyediakan fasilitas untuk pendamping PKH menjalankan tugas nya.

\section{Disposisi}

Suatu kebijakan untuk menunjang suatu program, komitmen dan kejujuran sangat penting dalam melaksanakan tahap-tahap program secara konsisten karena ketetuan dalam mengarahkan seorang pelaksana agar tetap berada pada panduan awal di dalam suatu program tersebut. Menurut George C. Edward III (2008) disposisi menunjuk karakteristik yang menempel erat kepada implementor kebijakan. Karakter yang penting dimiliki oleh implementor adalah kejujuran, komitmen dan demokratis.

Dari hasil wawancara di atas bahwa pemerintah desa atau perangkat desa dengan pendamping PKH tidak memiliki koordinasi secara terjadwal. Kepala desa hanya sebagai fasilitator dalam pelaksanaan PKH, sedangkan BPD sama sekali tidak terlibat dalam pelaksanaan program keluarga harapan. BPD hanya sebagai badan pengawas di Desa serta yang membuat rancangan peraturan Desa. Untuk pelimpahan wewenang pendamping PKH itu telah di tetapkan oleh pusat dan pemerintah hanya menerima kebijakan tersebut masuk di desa namun mereka tidak ada campur tangan dalam kegiatan saat di lapangan.

Hal ini bisa dikatakan jika pelaksanaan PKH di desa Mesigit menggunakan indikator disposisi dalam pelaksanaan kebijakan bantuan PKH namun masih kurangnya koordinasi oleh pendamping PKH kepada pemerintah desa.

\section{Struktur Birokrasi}

Struktur birokrasi juga sangat berpengaruh penting dalam suatu kebijakan program yang sedang dijalankan agar tidak terjadi tumpang tindih terhadap tugas yang dilaksanakan oleh implementor program. Dua aspek yang ada didalam struktur birokrasi yaitu mekanisme dan struktur organisasi. Menurut George C. Edward III (2008:31) 
Struktur organisasi menjadi penting dalam implementasi kebijakan. Aspek struktur birokrasi ini mencangkup dua hal penting yaitu, mekanisme dan struktur organisasi pelaksana sendiri. Mekanisme implementasi program biasanya sudah ditetapkan melalui Standar Operating Procedur (SOP).

Dari hasil wawancara dan observasi peneliti di lapangan, bahwa berdasarkan studi pustaka yang telah peneliti lakukan, koordinasi program PKH sudah tercantum dalam Permensos Nomor 01 Tahun 2018 dalam pasal 24 dan pasal 64 yang terkait dengan laporan hasil pelaksanaan PKH. Pembagian tugas PKH telah di bawah SK kementerian sosial oleh karena itu pembagian tugas dari pendamping PKH sendiri telah di tetapkan. Pendamping PKH melaksanakan tugasnya sesuai dengan mekanisme dan wewenang yang telah di tetapkan oleh pusat dan juga setiap bulannya pendamping PKH melaporkan hasil dari kegiatan yang telah mereka lakukan seperti pencairan dana dan laporan dari setiap kegiatan yang dilakukan oleh pendamping PKH.

Hasil penelitian menunjukkan bahwa, pelaksanaan PKH telah berjalan dengan baik, dan dari teori implementasi kebijakan terdapat 4 (empat) indikator yaitu komunikasi, sumber daya, komunikasi, dan struktur birokrasi. Pendamping PKH menggunakan semua indikator dari implementasi kebijakan untuk pelaksanaan PKH di desa Mesigit namun di setiap indikator masih memiliki hambatan dalam pelaksanaan bantuan PKH di desa Mesigit kecamatan Air Padang kabupaten Bengkulu Utara.

\section{SIMPULAN}

Pelaksanaan Kebijakan Program Keluarga Harapan (PKH) di desa Mesigit sudah berjalan dengan baik. Hal ini dapat dilihat dari ke empat indikator implementasi kebijakan berjalannya suatu komunikasi yang cukup baik di sampaikan melalui sosialisasi. Serta tersedia nya SDM yang mendukung dan fasilitas yang memadai. Terwujudnya disposisi yang dilaksanakan sesuai dengan wewenang dari pendamping PKH. Kemudian berjalannya struktur birokrasi untuk pelaporan di setiap kegiatan yang telah di laksanakan.

Adapun faktor penghambat pelaksanaan kebijakan bantuan PKH di desa Mesigit yaitu kurangnya kesadaran masyarakat akan pemanfaatan dari bantuan $\mathrm{PKH}$, kurangnya minat masyarakat untuk mengikuti kegiatan rapat tentang $\mathrm{PKH}$, terhambatnya fasilitas jaringan Telekomunikasi dan belum terlaksananya kegiatan rapat pada awal kebijakan masuk di desa. Tidak adanya koordinasi dari pendamping PKH kepada pemerintah desa dalam pelaporan di setiap bulannya.

\section{DAFTAR PUSTAKA}

Anggara, S. (2014). Kebijakan Publik.Bandung: CV Pustaka Setia

Anggraini, D. (2019). Faktor-Faktor Implementasi Program Keluarga Harapan di Kecamatan Sako Palembang. Jurnal Pemerintahan dan Politik, 3(3)

Darmi, T. (2018). Locally-Generated Revenue as A Capacity Parameters of New Regional Autonomy Management. JKAP (Jurnal Kebijakan dan Administrasi Publik), 22(1), $1-13$

Darmi, T., \& Mujtahid, I. M. (2019). Peningkatan Kapasitas Kebijakan Dana Desa Dalam Mengentaskan Kemiskinan. JIPAGS (Journal of Indonesian Public Administration and Governance Studies), 3(1)

Darmi, T., Suwitri, S., Yuwanto, Y., \& Sundarso, S. (2017). Capacity Building as Accelerator for Improving Autonomous Region Recently Knows as (DOB): Case Study in Seluma Distrcit Bengkulu Province, Indonesia. Journal of Public Administration and Governance. ISSN 2161-7104, Vol 7(3), pp.100-11

Dunn, W. N. (2003). Pengantar Analisis Kebijakan Publik Edisi Kedua. Yogyakarta: Gajah Mada Universit

Dwiyanto, I. (2009). Kebijakan Publik Berbasis Dynamic Policy Analisys. Gava Media: Yogyakarta. 
Edward III, George C. (1980). Implementing Public Policy. Washington DC: Congressional Quarterly Press

Indiahono, W. (2009). Kebijakan Publik Berbasis Dynamic Policy Analisys. Yogyakarta. Gava Media

Nugraha, I. (2018). Implementasi Program Keluarga Harapan Oleh Unit Pelaksana PKH (UPPKH) Dinas Sosial Kabupaten Lampung Timur

Khasanah, N. (2018). Pengaruh Sumber Daya Dan Disposisi Pelaksana Terhadap Keberhasilan Implementasi Kebijakan Program Keluarga Harapan (PKH) Di Kecamatan Bandongan Kabupaten Magelang. JMAN jurnal mahasiswa Administrasi negara, 2(2), 30-35

Moleong, J., L. (2009). Metode Penelitian Kualitatif. Bandung: PT. Remaja Rosdakarya Nugroho, R. (2003). Kebijakan publik: Formulasi, Implementasi Dan Evaluasi. Jakarta: Elex Media Komputindo

Purwanto, S. A., Sumartono, S., \& Makmur, M. (2013). Implementasi Kebijakan Program Keluarga Harapan (PKH) Dalam Memutus Rantai Kemiskinan (Kajian di Kecamatan Mojosari Kabupaten Mojokerto). WACANA, Jurnal Sosial dan Humaniora, 16(2), 79-96

Sasmito, C., \& Nawangsari, E. R. (2019). Implementasi Program Keluarga Harapan Dalam Upaya Mengentaskan Kemiskinan di Kota Batu. JPSI (Journal of Public Sector Innovations), 3(2), 68-74

Subarsono, A., G. (2005). Analisis Kebijakan Publik: Konsep, Teori Dan Aplikasi (Vol. 138). Pustaka Pelajar: Yogyakarta

Sugiyono, S. (2011). Metode Penelitian Kualitatif Kuantitatif Dan R\&D, Alfabeta: Bandung

Suharto, E. (2013). Kebijakan Sosial: Sebagai, Kebijakan Publik. Alfabeta: Bandung

Syafie, I., K. (2006). Sistem Administrasi Republik Indonesia (SANRI), Bumi Aksara: Jakarta. 